\title{
Synergity of Health Services to the Interaction of Healthy Life Behavior of Rural Communities in South Sulawesi
}

\author{
Darwis, M. Kes ${ }^{1}$ \\ ${ }^{1}$ Lecturer, College of Health Sciences (STIKES), Nani Hasanuddin Makassar, Indonesia \\ Correspondence: Darwis, M. Kes, College of Health Sciences (STIKES), Nani Hasanuddin Makassar, Indonesia.
}

Received: June 4, 2019

Accepted: June 20, $2019 \quad$ Available online: June 27, 2019

doi:10.11114/ijsss.v7i4.4354

URL: https://doi.org/10.11114/ijsss.v7i4.4354

\begin{abstract}
Types of qualitative research through the phenomenological approach, the results showed that health services in the area is not optimal, it is seen that health care is still dominated by Puskesmas, while for diseases Conducted by referring to hospitals that have a better scale and handling, this is because Puskesmas has limited service in terms of facilities, medical personnel, drugs etc., other than that the community is increasingly The day, the more economic access would require better service so that many people choose treatment in the city that has better facilities.
\end{abstract}

Keywords: service, health, interaction, behaviour, healthy

\section{Introduction}

\subsection{Background}

Health development aims to increase awareness, willingness and healthy living ability for everyone to manifest the optimal degree of public health. To realize the health degree for the community held health efforts with the approach of pemeliharaan, health Enhancement (PROMOTIF), prevention of diseases (preventive), healing of the disease (curative), and recovery of health ( Rehabilitation) that is carried out thoroughly, integrated and sustainable.

One of the leading technical implementation unit of health in the area that almost evenly in each sub-district and relatively close to the target of health development program is Puskesmas. As a spearhead, Puskesmas conducts basic health services integrated with functions as a basic health care center, health-oriented development center and as a role-playing center for the community in Health development. Therefore, as a leading technical implementing unit Puskesmas and its network must be supported with adequate resources, one of them is with the support of costs for the activities operational Puskesmas and network.

The development of health is essentially an effort undertaken by all components of Indonesia that aims to increase awareness, willingness, and healthy living ability for everyone to materialize the degree of public health that Highest, as an investment in the development of socially and economically productive human resources (Ministry of Health RI, 2015).

To achieve optimal health, it is done by a wide range of health services, directed and sustainable. According to Blum (1974), that degree of health is influenced by several factors i.e. environment, behavior, health care and heredity. A very large impact on health is the environmental circumstances that do not meet the health requirements and behaviors of the detrimental community, both rural and urban communities that are caused by lack of knowledge and ability Health, Economics and Technology (Ministry of Health, 2004). The interactions of various factors exist, both internal factors (from human beings) and external (outside human beings) factors that interacted with each other to be image in the degree of public health.

A common problem that is always seen in every village community or city community in relation to health, is the change and addition of health knowledge as well as changes in health behaviour that is action and should always be done . A community especially the village community is increasingly traditional and low in education, and closed from public information will be increasingly slower processes understanding, acceptance and adoption of knowledge information, values and New health practices in addressing health problems and increasing the degree of community health in question.

Accompanying these general problems are specific problems that exist in the village community that can inhibit the 
prevention and improvement of health in the form of culture, social, psychic, poverty and ecological issues, especially economic relations People with limited resources. These problems, in other words cause the efforts of health programs do not always run smoothly and intermittently, some even lack of success or even fail at all.

The concept of health development in the village that has been applied bias through the perspective of the city, because it uses a community health development approach in the city, which is also measured based on indicators of the city community progress. Social culture of the village community is not considered distinctive, but is humbled or considered imperfect, based on the relative size of the social culture of the city community. The emergence of the concept of public health development by based on the village requires a change of development paradigm itself, namely by abandoning the development of the village by the city's perspective, because it will never see the village as A distinctive socio-economic and cultural entity. The village should be approached and touched with a specific approach so that its potential can be shaken and optimally developed. Foster (1978) states that health programs in developing countries will be able to succeed if the planning and implementation is taken into account carefully the social, cultural and psychological characteristics of the group Program targets. Everyone is entitled to health and everyone has the same right to gain access to resources in the field of health. But in addition, everyone also does not escape the obligations in the health field. Therefore, the Government has a number of responsibilities that must be performed, which includes the responsibility to plan, regulate, organize, build, and supervise the implementation of health efforts that are evenly and affordable by the community. The Government also has the responsibility to empower and encourage the active role of society in all forms of health efforts.

\subsection{Formula Problems}

1. How is health service in rural communities in South Sulawesi?

\subsection{Purposes}

1. To know health services in rural communities in South Sulawesi?

\section{Literature Review}

\subsection{Synergity}

Synergy is a term used to describe a situation when different entities work together profitably for one end result. Simply put, synergies are filling each other and completing differences to achieve a final goal. Simply put, it means the whole of synergy will be greater than the sum of each section.

Synergy is not a compromise synergy is not equal to compromise. In compromise, the parties involved must sacrifice some of the objectives in order to cooperate. Synergy means mutual respect for differences in ideas, opinions and willing to share with each other. The synergy is not selfish, but thinks win-win and no party is harmed or feels harmed. Synergy aims to combine separate parts.

Tips for building Synergy:

Synergy is a process that each party must pass through, which takes time and consistency. Things that need to be done to build mutual trust so that synergy awakened as a creative cooperation including:

a. Make it to others as you want to be treated by others

b. Do not judge poorly against other parties

c. Do not give promises that you are unsure of fulfilling

d. Do not disappoint the expectations of others

Creating synergies is a common success that is built from habits. Creating synergy does not mean compromise in the center, but instead seeks a third alternative and reaches the top. Synergy is a difference not an equation. Synergy will build creative cooperation by respecting differences, building strength and compensating weaknesses.

In the world of human resource empowerment, this phenomenon makes it clear that hard skill mastery alone is not enough. Everyone needs to improve their soft skillability. A well-applied Soft skill can affect the rating of the supervisor despite the ability of the hard skills not yet as well as expected. Soft skill Mastery has always been a positive influence on career. The question, if indeed soft skill is really so important, why many people are reluctant to master soft skills? Obviously here that for most people soft skills are still considered not very important.

Hard skills are the usual skills to be learned at a school or university that aims to improve the intellectual ability associated with operational technical work. While Soft skills, generally people think that this skill is a life skill to be a person who is "personality". A warm and tender, full of manners, a slick word, etc. In fact these things are just a fraction of the soft skills, because the truth with this skill allows you to be more effective using technical skills and factual 
knowledge.

Soft skills include interpersonal and intrapersonal skills. Interpersonal skills such as socializing, adapting and communicating. Intrapersonal includes the skill of managing feelings, reflecting, correcting yourself and conducting self-talk. Indeed, the scope of soft skills is very wide covering the capabilities and characteristics of human beings such as: self awareness, trustworthy, conscience, able to adapt, critical thinking, behave, initiative, empathize, confident, self-integrity, self-control , organizational awareness, friendly, influential, dare to take risks, can solve problems, have a leader spirit, have time management, and some others

\subsection{Public Administration}

In the past, administrative sciences were seen as normative science that emphasized "whatshould be", but the current developments, the view was demistification, and experts saw the administration as the Policyscience Combining the question "What should be" with "what is" in the form of the question "what is probable" so further; Moeljarto in Marlon (2009).

The public administration of each country has a number of certain features "how things Are Done", which differs from country to country. In addition, in every administration there are many institutions with their own distinctive characteristics: local, provincial or regional, national and even transnational institutions (in Dr. Enrique Claver, Dr. Juan Llopis and Dr. José L. Gascó, 2000). Most public administration theories (Frederickson 1997; Perry and Wise 1990 in Wouter Vandenabeele, 2007) identify such behaviour as self-sacrifice in realizing the public interest and altruism as the specificity of civil servants and very difficult to explain the type of behaviour in terms of Rational Choice (Wouter Vandenabeele, 2007).

The proper role of society in Public administration has been an active and ongoing area of investigation, experimentation, revolution, and controversy since the birth of this nation. Contemporary movements to test the role of society in the process of making administrative decisions have come in response to problems in the second half of this century and as a result of concerns on the part of citizens, administrators, and Politicians are more on the desperation of citizens and apathy (Box, 1996; Putnam, 1995, Timney, 1996; Thomas, 1995 in Cheryl Simrell King, Kathryn M. Feltey and Bridget O'Neill Susel, 1998). Because both things citizens and their leaders have realized, "participation through normal institutional channels has little to no effect on the government's political substance" (Crosby, Kelly, and Schaefer, 1986 in Cheryl Simrell King, Kathryn M. Feltey and Bridget O'Neill Susel, 1998). Many residents, administrators, and politicians are interested in increasing the decision of public participation in society. Attempts to do so are currently underway throughout the country (Cheryl Simrell King, Kathryn M. Feltey and Bridget O'Neill Susel, 1998).

Administration as an art because in implementing it using skills that reflect individual abilities, as stated by Siagian that the administration is other than as artistic science as well as Scientificart. Administration requires ethics in serving the interests of society. As Plato's in Irawati (2007) says that Onecannot be a good public administratorwi thout being first a philosopher.

Bellone (Irawati, 2007) argues that the discipline of public administration is predicated on the study of organization. Organizational theory, hypotheses about human behaviour in complex governmental organizations and administrative theories and hypotheses about human behaviour in the Working Group, are fundamental to the theory of public administration. It can be explained that public administration talks about human behaviour in government organizations. Even Shafritz and Russell (2005:5) in Irawati, 2007) posited; It is easy to define administration if you are content with being simplistic: it is governmnet in action - the management of public affairs on the implementation of public policies.

The verdict on the existence of public administration as part of this political science is also supported by Allen Schick who believes that public administration is essentially devoted to power and has full power to do Devotion to assist the ruler in ruling more efficiently (Thoha, 2002:33 in Anwaruddin, 2004).

This kind of thought was primarily put forward by Dwight Waldo (1953) (Anwaruddin, 2004) who gave a sense of public administration, that "Publicadministration is the organization andmanagement of men and materials to achievethe purpose of government".

\subsection{Service}

According to Munir in Hendra Hadiwijaya (2011:224) service is an activity that a person or group of people with the foundation of material factors through certain systems, procedures and methods in order to fulfill the needs of others according to Right. This explains that service is a form of system, certain procedures or methods given to other participants in this case customers so that the needs of these customers can be fulfilled in accordance with their expectations.

Friendly and professional service has become a condition that must be fulfilled by the organizers of the State 
administration (Waworuntu in Suratno, S.Ag., MAP, 2013). Siagian in Hasma Erpianti H (2009:9) expressed service is often interpreted as a caring activity, preparing something either in the form of goods or services to the users (stakeholders), customers (users) and consumers. It is also expected that both the climate service in the working unit, the customer's assessment of the better of the employees will the quality of service (i.e., the performance of employees). Finally, customers are more loyal to the organization when they assess the performance of more positive employees (Marisa Salanova and Sonia Agut, 2005).

Empirical evidence suggests that, with employees capable of delivering high-quality services to the extent that employees are capable, customers are more likely to evaluate favorable outcomes of meeting service, high experience satisfaction, and Increase their purchase and the frequency of their future visits (e.g., Borucki \& Burke, 1999; Bowen, Siehl, \& Schneider, in Hui Liao and Achia Chuang: 2004).

According to Munir in Hendra Hadiwijaya (2011) Service is an activity that a person or group of people with the foundation of material factors through certain systems, procedures and methods in order to fulfill the needs of others according to Right. This explains that service is a form of system, certain procedures or methods given to other participants in this case customers so that the needs of these customers can be fulfilled in accordance with their expectations.

Tjipton (1998) in Hendra Hadiwijaya (2011) expressed the quality of service/service is the level of excellence to meet the wishes of customers. In that opinion a quality of service or as an advantage-given the company in order to fulfill the wishes of customers. Meanwhile, according to Siagian (1998) in Hendra Hadiwijaya (2011) service in general is a sense of fun that is given to others along with facilities and meet all their needs.

Thus the service is an effort to provide pleasure to customers with the convenience of the customers can fulfill their needs. Payne (2000) in Hendra Hadiwijaya (2011) expressed the quality of services relating to the ability of an organization to meet or exceed customer expectations.

Friendly and professional service has become a condition that must be fulfilled by the organizers of the State administration (Waworuntu in Suratno, S.Ag., MAP, 2013). According to Munir in Hendra Hadiwijaya (2011:224) service is an activity that a person or group of people with the foundation of material factors through certain systems, procedures and methods in order to fulfill the needs of others according to Right.

Siagian in Hasma Erpianti H (2009:9) expressed service is often interpreted as a caring activity, preparing something either in the form of goods or services to the users (stakeholders), customers (users) and consumers.

\subsection{Public Policy}

The public policy process, at least, includes: 1) formulation of problems; 2) forecasting; 3) Recommendation; 4) monitoring; 5) evaluation. Innovative public policies must always be: 1) based on the public interest; 2) planning, implementation, and supervision, and evaluation involving public participation; 3) The housing is constantly moving dynamically according to the development of public aspirations.

Michael E. Porter in Susy Susilawati (2007) explained that the competitive advantage of each country is determined by how capable the country is able to create an environment that grows the competitiveness of every actor in it. In the context of global competition, the task of public sector is to build an environment that allows every development perpetrator to develop themselves into competitive actors.

Thomas R. Dye defines that "Public policy is whatever government chose to do or not. To do "(Whatever the government has chosen to do or not done). From this definition, the public policy covers everything that is stated and done or not done by the government. In addition, public policy is also the policies developed/made by agencies and government officials.

In this case the public obstetric theory that the author used was a public obstetric theory according to Thomas R. Dye stating that public policies were what the government did and what the government did not do.

One of the important things related to public policy is the process of creating a public policy. According to Thomas R. Dye Public Policy making process is a political process involving various interests and resources so that the end of the political process is a subjective product created by the conscious choices of perpetrators Policy.

\subsection{Health Services}

The health services according to the experts are:

\section{According to Prof. Dr. Soekidjo Notoatmojo,}

Health care is a sub-system of health services whose primary purpose is the preventive and promotive services (health improvement) with the target community. 


\section{According to Levey and Loomba (1973)}

Healthcare is an effort that is held alone or jointly in an organization to maintain and improve health, prevent, and relieve diseases and restore the health of individuals, families, groups, or community.

\section{According to Azrul Azwar (1996)}

Health care is every effort held by itself together in an organization to maintain and improve health, prevent and cure diseases and restore the health of individuals, families, groups and or community.

Based on the above definitions, we conclude that healthcare is a sub-system of healthcare services whose primary purpose is promotive, preventive, curative, and rehabilitation of individual health, family, group or Community, Environment.

\section{Research Methods}

Types of qualitative research through the phenomenological approach

\section{Discussion}

\subsection{Health Services in Rural Areas of South Sulawesi}

Health services can be obtained starting from the level of puskesmas, hospitals, physicians of private practice and others. Today, people are increasingly critical of health services and healthcare professionals. The community demands good health services from the hospital, on the other hand the government has not been able to provide services as expected due to limitations, except the private, business-oriented hospitals, can provide health services well.

To improve healthcare services needed skilled health workers and good hospital facilities, but not all hospitals can meet these criteria so that the increasing complexity of the health care system is today.

One of the assessments of health care can be seen from the recording of medical records or health records. From the recording of medical records can improve the quality of health services given to patients, also to the importance of health care law, education, research and hospital Accriditasi.

\subsection{Condition of Service Capital of South Sulawesi}

Health service condition in the city of Makassar which is the capital of South Sulawesi province is increasing, along with that the level of public satisfaction is increasing. Although government work has not reached a maximum number of $100 \%$. The Data that SINDOnews acquired, improving its main healthcare service in the Homecare program increased from the previous year. Ministry of Health (Dinkes) Makassar noted, the community served in the year 2018 reached 7,366 people, in the past year only around 4,685 lives served directly in their homes.

Secretary of Dinkes Makassar, Dr Tasmin also explained, the level of satisfaction of the community for the Puskesmas service reaches $81.77 \%$ (predicate VERY GOOD), or increased from the previous year that amounted to $81.71 \%$. "The number of patient referrals served in Makassar HOSPITAL as much as 44,294 patients from a total of 44.0-440 patients or at $99.67 \%$, while another sick Tara 146 patients are referred to another hospital," said Tasmin at the meeting of budget agency related Ranperda Accountability for implementation of APBD TA 2017 in Banggar meeting Room of PARLIAMENT of Makassar, Saturday (28/7/2018).

Meanwhile, from the medical record, the nutritional prevelency is less $6.90 \%$, or successfully derived from the previous year, which amounted to $7.64 \%$, a bad nutrient prevelency of $2.03 \%$, or also managed to be lowered from the previous year, which amounted to $2.06 \%$. "A number of indicators that have been said to give the idea that health services have been progressively better year after year," he concluded. For the achievement, member of the budget board of DPRD Makassar, Rahman Pina admitted that the improvement of Puskesmas service is much better than the previous years. He even praised some of the innovations done by the Puskesmas to improve services, such as children's space, breast milk, etc. "In the past, the Puskesmas is no different from the Puskesmas in the area. And if we compare with now, much better, because we have the pride of the change of puskesmas that exist in the Puskesmas now, "he said.

\subsection{Health Care Strategy in South Sulawesi}

Health service Quality Improvement efforts include:

\section{Organization Setup}

Structuring the organization into an efficient, effective organization with unoverlapping structure and task description, and a clear working relationship with adhering to the organization through the function principle.

\section{Regulation of legislation}


A comprehensive assessment of the existing legislation and regulations that support the implementation of the above policies.

\section{Network integration}

The development and improvement of the network with the excellent center of service and the reference system will greatly improve the efficiency and effectiveness of health care, so that thereby will improve the quality of service.

\section{Standardization}

Standardization is an important activity that must be implemented, including both quantitative and qualitative energy standards, facilities and facility, capabilities, methods, recording and reporting, etc. The expected external should also be standardized.

\section{Human resource development}

The ongoing and ongoing implementation of various education and training to produce professional, competent and moral and ethical human resources, has a high dedication, creative and innovative and $\mathrm{Be}$ anticipatory to the various changes that will occur both locally and globally.

\section{Quality Assurance}

Various components of quality assurance activities should be implemented immediately followed by the planning and implementation of various improvement and improvement efforts to achieve service quality improvement. Data and information obtained by careful dianalysis (root cause analysis) and followed by drafting the appropriate corrective action involving all stakeholders. All this is done with the "Tailor's Model" and Plan-Do-Control-Action (PDCA) approach.

\section{Development of Science and technology}

The development of science and technology is done by establishing cooperation and collaboration with superior centres either locally or domestically or internationally. The implementation of such science and technology development should be done taking into consideration the financing aspect.

\section{Increased participation of community and professional organizations}

Improvement in the role of professional organizations, especially in the development of members in accordance with professional standards and quality improvement of human resources.

\section{Improved social control}

Improvement of public supervision and control over the implementation of health services will increase accountability, transparency and quality of service.

\subsection{Factors Affecting Health Services in South Sulawesi}

\section{New Science and technology}

To remind the development of science and technology, it will be followed by the growth of health care to overcome the problems of diseases that can be used difficult tools such as leser, Gene use therapy and others

\section{Community Value}

With the diverse community, it can lead to the utilization of different health care services. People who have advanced with high knowledge, it will have a deeper awareness of use or utilization of health care services, as well as vice versa.

\section{Legal and ethical aspects}

With the high public awareness of the use or utilization of healthcare services, the higher the legal demands and ethics in healthcare services, so that the perpetrators of healthcare providers should be required to Providing health services in a professional manner by observing the legal values and ethics that exist in the community.

\section{Economy}

The higher one's economy, health care will be more attention and easy to reach, and vice versa, this economic situation will be able to affect the health service system.

\section{Politics}


Government policy through the existing political system will be more influential in the system of providing health services. Existing policies can provide patterns in the service system. (Aziz, Alimul. 2008).

\subsection{The Cause of Low Quality of Service in Hospitals}

Many reasons why the service in South Sulawesi is low primary service actors who do not have the competence and adequate authority, so that the treatment of disease is not appropriate standards, and often occurs the use of various drugs Inappropriately that ultimately resulted in the ineffectiveness of costs, and also other problems such as drug resistance due to the use of antibiotic drugs.

"Society in the weak economy class tends to choose the closest and cheaper health service, regardless of whether the officer he/she is in the aid has adequate authority and competence. While the community in the economy class tend to directly check themselves into specialists with various risks of inaccuracy the selection of specialist doctors that he chooses, "said Nugroho. "

Indonesia as a big country certainly has big consequences also in various problems. Starting from economic problems, socio-political, education, health and so on.

Based on the IPM report issued by the United Nations Development Program (PBB) 2013, for Maternal mortality (AKI) in Indonesia the number is still very high, which is defective 220 per 100,000 live births, while in neighboring countries ASEAN, such as Singapore listed its number of 3, Brunai 24, Malaysia 29, Thailand 48, Vietnam 59, and the Philippines by 99. Indonesia is only better than Cambodia, Laos and Timor Leste.

Related to sanitation problems, as reported from UNICEF 2013 data, Indonesia is at 2nd order as the lowest sanitation country in the world. The first position of India is about 626 million people living without sanitation, while Indonesia as many as 63 million persons recorded has not had a toilet or MCK so no surprise the outbreak of diarrhea is still one of the causes of high numbers Infant death in Indonesia. Worldwide from 600 thousand children died annually from diarrhoea and Indonesia itself is one of the 11 countries of the highest mortality due to the illness.

\subsection{Village Authority in the Development of Public Health}

The village has a duty to improve public health. In order to achieve this, LAW 6/2014 about the village has ensured the local authority of the village scale, one of which is the authority to conduct public health development

The realization of activities in the framework of Community health development, as intended in Permendesa 1/2015, section 34 of which are (1) development of village health post and Polindes; (2) Development of village health workers; (3) The management and construction of Posyandu; (4) The coaching and supervision of traditonal health efforts; (5) The Monitoring and prevention of narcotic abuse in the village.

In point (3) the management and coaching of Posyandu is given some of the description of which (a) nutritional services for toddlers; (b) The examination of pregnant women; (c) Provision of additional food.

By referring to the existing regulations, the village has the authority to perform the construction of Posyandu and its services. That is, the village community can ask the village government to discuss various health issues in the village in the village deliberation forum.

Important matters regarding the degree of public health in the village can be discussed and prioritized in village planning. Strengthening the capacity of Posyandu cadres is also a village authority in the empowerment of community and village Community institutions. One of the main things for the village community is the improvement of Community welfare, and among them through improved public health. People are healthy, it will go to prosperous community.

To make health a priority at the village level, it is necessary to have a strong commitment, especially from the village head. And the things that are the local authority of the village scale is not only like in the regulation of the minister, but actually leads to improving the quality of health services. Quality improvement of course is related to the provision and close access to health services to the citizens.

On the other hand, citizens also need to make this health problem as one of the priorities that will be carried out in the village Musawarah. Villagers need to do adequate research, so that their proposals become qualified, and putting health matters is not a mere woman's business. This happened in many villages in Indonesia, when discussing health affairs then the focus is the Posyandu cadres or PKK village administrators. In fact not only that, the goals of health programs also lead to women. Women are still the subject as well as health promotion objects.

Through the local authority of the village's scale, to improve the health of its citizens, it will be interesting if the village is able to make programs and indicators success increase the health degree of its citizens. If we hope that the village is still too far away (perhaps), then at least the district government can start to help formulate the indicators of the healthy 
village and invite the village and Stakeholdersnya to jointly make efforts to Achievement of the matter.

\subsection{The Welfare of Health-Based Communities}

Village communities as a community of legal communities that have their own territorial boundaries and authority, they can organize and manage the affairs and interests of the society, based on their initiatives. Initiatives or community participation in the efforts to achieve health development goals need to be pushed together to create a community setting with a "healthy village" paradigm that directly implicates the increase Health and welfare status of the village community.

The concept of healthy village is a movement to create or realize a village with a condition of society that has knowledge about health including nutrition, able to apply the pattern/culture of living healthy and clean both temporal and spiritual. In addition, it is also to realize a healthy, clean, neat environment by being able to utilize the natural resources that exist for the survival of both self and others and also healthy in the sense of economically independent. Indeed, in realizing a healthy village is not easy, because there are various aspects that play, ranging from socio-cultural aspects, education, regional policies to village community awareness to want to change the mindset and Their habits that have not been in line with a clean and healthy lifestyle. In this context the improvement aspect of public education needs to be continuously improved through various socialization and simulation activities regarding health problems that usually arise in the community so that there is understanding and basic knowledge, Which in itself will stimulate the changing behavior of healthy living in the community.

\subsection{Healthy Village Indicators}

A village with a healthy category must have an indicator of its achievements, including: 1) increased capacity of PKK and Posyandu cadres to support the realization of family welfare, including: environmental hygiene, PHBS, family nutrition, education Family, home industry (increased family income); 2) The nutritional conscious movement. Indicators of KADARZI (nutritional conscious family) include: weigh regularly, give breast milk only to infants from birth to the age of 6 months (exclusive breast milk), a variety of meals, using iodized salt, taking nutritional supplements (tablets added Blood, capsules of Vitamin A high dose) as recommended; 3) PHBS movement by cultivate the habit of CTPS (hand wash soap) and SGPM (morning toothbrush) correctly and precisely both the way and time of implementation; 4) The movement of household waste management independently by separating organic and inorganic waste and then processed into beneficial products; 5) Healthy latrines movement, where the Ministry of Health has set the conditions in making a healthy latrines, with the following criteria: not polluting the water and soil surface, free from insects, do not cause odor and comfortable to use, safe to use By the wearer, easy to clean and not cause interference for the wearer and does not pose a less polite view.

The five indicators above are the responsibility of all components of the village community, whether the village government apparatus, also no less important is the role of youth leaders, religious/indigenous figures, educators and community NGOs (NGOS). All these components can be jointly committed to encourage all villagers to be aware of the importance of establishing a concept of a healthy village paradigm for the efforts to improve the quality of life together in the community.

Especially now with the policy of the central government through the allocation of village funds (ADD) that can be utilized by village government apparatus to plan various programs that mature both short-term programs, medium and long-term Long-term public health. Certainly the implementation of this program is expected to participate by involving all elements of the village community so that there is a shared responsibility of all citizens to the evaluation and achievement of the program that implications for improving health status and welfare of society.

\subsection{The Role of Village Society}

Healthy Village Program is an empowerment movement of the potential of citizens and community of villagers in creating a healthy family and environment. Empowering villagers as an effort to develop community self-reliance and welfare by enhancing the knowledge, attitudes, skills, behaviors, abilities, awareness, and leverage of resources through policy setting, Programs, activities, and mentoring that fit the essence of the problem and priority of the needs of the village community. So there are synergistic efforts from all the components of the village community with their respective roles committed to providing the principles of healthy living in all aspects of life.

Creating a "healthy village" needs the totality of community participation, while institutions or health care institutions are merely motivators or advisers in public health efforts. The role of village community in the health field should be manifested in the effort to encourage every individual, family and or community institution including taking the private responsibility for the health of Self, family and society.

To make a healthy living society, according to the author for the state of Indonesia as a developing country, must start from a change of mindset, meaning that people need to get the awareness to understand seriously that health Very 
important, so that healthy lifestyle needs the public to know both through formal education and can through non-formal education, for example the village government with doctors, nurses down to the community provide guidance, Counseling so hopefully there is change after the community get guidance about healthy lifestyle, so far most people are not very concerned about health, their mindset kalu sick them to doctors in Puskesmas, after recovering They are returning to their activities, while the advice of doctors generally tends to be ignored.

By developing the ability to nourish oneself, family and society and its environment and become a pioneer of health and leaders who mobilize community activities in the health sector based on independence and togetherness The effort to reach a healthy village can be done more thoroughly.

The paradigm of "healthy village" is certainly a hope for all villagers in the joint effort to organize a better community life and active role. In this condition, people who will create a village government, and village community that has the optimal degree of health, behave in a healthy and clean life so as to be productive, competitive, independent, happy and prosperous

\section{Conclusion}

Health services play an important role in improving people's welfare, health is not alone but there must be awareness to the community about the significance of health, people in rural communities get health care From Puskesmas, where the Puskesmas has limited health services, both from the aspect of facilities, paramedic, physician and drug personnel, so that the treatment that can be not optimal, the condition causes the Puskesmas to do Actions in the form of recommended patients to a more complete hospital in other areas, so between the needs of the community and healthcare services still need to be improved.

\section{References}

Ali, Z. (2000). Introduction to Nursing service in Puskesmas; 6 Series Public health care, Depok.

Arja, S. (2000). "Accountability and measurement of government Performance". Journal of Accounting \& Finance, 2(2).

Azwar, A. (1996). Introduction to the Health Administration of the third edition. Tangerang: Binapura Aksara.

Bambang, S. (2010). "The effect of remuneration on the quality of public services". Business \& Bureaucracy. Journal of Administrative and Organizational sciences, 17(1).

Celine, S. (2013). "Theory of public Administration",

Chairun, N. (2013). "Public administration reform: A conceptual study". The Scientific Journal of Public Administration and Development, 4(2).

Depkes, R. I. (1987). community participation, education and training Center for employees, Jakarta.

Dyah, H. (2008). "Complaint management and complaints handling in public services". Journal of Administrative Sciences and public policy "Dialogue" JIAKP, 5(2).

Effendi, N. (1998). Public health Fundamentals, Ed. 2, EGC, Jakarta.

Elvira, Z. (2011). "The influence of good governance and the government accounting standards for financial accountability with the commitment of the Organization as a moderate". Accounting and Accountancy Reviews, 1(1), ISSN: 2088-0685.

Endang, L. (2008). "Public ServicesReform and Public Participation". Journal of Administrative Sciences and public policy "Dialogue" JIAKP, 5(2).

Felicia, G. (2007). "Political Economy of advertising in Indonesia against the concept of Beauty". Scientific Journal SCRIPTURA, 1(1), ISSN 1411-XXXX.

Ferry, R. (2011). "Transaction Cost Theory".

Habsul, N. (2013). "new Political Economy: from understanding to the development empirical example".

Hendrikus, T. G. (2007). "Executive Institutional Accountability". Journal of Administration, 4(1).

Heryanto, M. (2010).“Efektivitas dan Efisiensi Penyelenggaraan Pelayanan Publik: Suatu Tinjauan Kinerja Lembaga Pemerintahan". Naskah Publikasi 2010.

Irawati (2007). "Renewal of administration and bureaucracy (an Era of Change)", the Civil Journal edition I/May 2007.

Koentjoro, T. (2007). Health regulation in Indonesia. C. V Andi Offset. Yogyakarta.

Luluk, L. (2012). "The basics of Individual behaviour".

Mubarak, I., Wahid, S., \& Chayatin, N. (2009). Public health Sciences. Salemba Medika: Jakarta. 
Reynaldi, R., \& Nur, A. P. (2011). "Factors affecting the Accountability of government agencies (studies on the Working unit of regional devices of Rokan Hulu)", Journal, 3(3).

Sad Dian Utomo. (2008). "The public complaints handling Of the Community service \& Bureaucracy". Journal of Administrative and Organizational sciences, 15(3).

Silalahi, B. P. S., \& Silalahi, R. (1991). Occupational safety and health management. [S. 1]:P Ustaka Binaman Pressindo.

Suma'mur. (1985). Occupational safety and accident prevention. Jakarta: Mount Agung, 1985.

Teguh, K. (2009). "The role of public accountability and community participation in the eradication of corruption in government", Business \& Bureaucracy. Journal of Administrative and Organizational Sciences, 16(2), 116-121. ISSN 0854-3844.

Teni, L. (2007). "Implementation of transparency policy and accountability of public services (study in PDAM Bandung City)". Journal of Administration, IV(3).

\section{Copyrights}

Copyright for this article is retained by the author(s), with first publication rights granted to the journal.

This is an open-access article distributed under the terms and conditions of the Creative Commons Attribution license which permits unrestricted use, distribution, and reproduction in any medium, provided the original work is properly cited. 